\title{
Survival of Phytophthora infestans in Surface Water
}

\author{
Lyndon D. Porter and Dennis A. Johnson
}

First author: Department of Plant, Soil and Entomological Sciences, University of Idaho, Aberdeen Research and Extension Center, Aberdeen 83210; and second author: Department of Plant Pathology, Washington State University, Pullman 99164. Accepted for publication 9 December 2003.

\section{ABSTRACT}

Porter, L. D., and Johnson, D. A. 2004. Survival of Phytophthora infestans in surface water. Phytopathology 94:380-387.

Coverless petri dishes with water suspensions of sporangia and zoospores of Phytophthora infestans were embedded in sandy soil in eastern Washington in July and October 2001 and July 2002 to quantify longevity of spores in water under natural conditions. Effects of solar radiation intensity, presence of soil in petri dishes (15 g per dish), and a 2-h chill period on survival of isolates of clonal lineages US-8 and US-11 were investigated. Spores in water suspensions survived 0 to 16 days under nonshaded conditions and 2 to 20 days under shaded conditions. Mean spore survival significantly increased from 1.7 to 5.8 days when soil was added to the water. Maximum survival time of spores in water without soil exposed to direct sunlight was 2 to 3 days in July and 6 to 8 days in October. Mean duration of survival did not differ significantly between chilled and nonchilled sporangia, but significantly fewer chilled spores survived for extended periods than that of nonchilled spores. Spores of US-11 and US-8 isolates did not differ in mean duration of survival, but significantly greater numbers of sporangia of US-8 survived than did sporangia of US-11 in one of three trials.

Additional keyword: late blight.
Late blight, caused by Phytophthora infestans, is one of the most costly and damaging potato diseases worldwide. Management expenses in the field and tuber losses in storage were estimated to be $\$ 22.3$ million in the Columbia Basin, WA, in 1998 (20). Losses in storage due to tuber rot were estimated to be $\$ 3.0$ million in the Columbia Basin of Oregon and Washington in 1995 and \$1.4 million in 1998 (20,21). Tuber rot due to P. infestans in the field and in storage facilities in the Pacific Northwest is a continuing concern.

Tubers become infected in the field when zoospores or sporangia of $P$. infestans are washed from infected stems or leaves and come in contact with tubers. Tuber infection occurs through buds, lenticels, and wounds $(23,46)$. The inner starchy tissue of infected tubers appears rusty red to dark brown, and initial lesion spread is most apparent just under the periderm of the tuber.

Survivability of zoospores and sporangia of $P$. infestans is a paramount component to understanding late blight epidemics. Many factors impact survival of sporangia and zoospores includeing solar radiation $(34,38,39,43)$, temperature $(10,27,28,35,41)$, moisture $(11,15,36,45)$, soil chemistry $(2-5,8,18)$, soil microorganisms $(25,26,36,46)$, and spore physiology $(7,12,29,37,38)$.

Survival of sporangia, zoospores, and mycelia of $P$. infestans in soil has been observed in controlled and natural environments. Zoospores survived for 10 days, sporangia for 42 days, and mycelia for 28 days in vitro in nonsterile soil at $22^{\circ} \mathrm{C} \mathrm{(46).} \mathrm{The} \mathrm{maxi-}$ mum survival of sporangia in vitro in nonsterile soil was 70 to 80 days $(24,27,39,46)$. Survival of $P$. infestans propagules under natural environmental conditions in naturally infested soil and in artificially infested soil in pots was 21 to 32 days $(26,36)$. Survival depended on soil type and moisture content $(26,36)$.

Noticeably absent from the literature is information on the survival of $P$. infestans propagules in surface water under natural environmental conditions. In the Columbia Basin, initial late blight

Corresponding author: L. D. Porter; E-mail address: 1dporter@uidaho.edu

Publication no. P-2004-0217-01R

(c) 2004 The American Phytopathological Society foci are often found in areas where surface water has collected in potato fields (19). Most potato fields are irrigated using overhead center pivot irrigation, and surface water is common along the wheel lines, in places where pivots overlap, in field depressions, and in over-irrigated potato fields.

Understanding the survivability of $P$. infestans propagules in surface water, especially under the semiarid environmental conditions that prevail in the Columbia Basin, is essential to understanding the risk of $P$. infestans infection and possible dispersal from standing water. The purpose of this study was to quantify spore survival over extended sampling periods in surface water under natural environmental conditions and to assess the effects of UV radiation (UVR), a 2 -h chill period at $10^{\circ} \mathrm{C}$, and the presence of soil in the water on spore survival of US-8 and US-11 isolates of $P$. infestans.

\section{MATERIALS AND METHODS}

Survival of sporangia and zoospores of $P$. infestans in surface water was studied during July 2001, October 2001, and July 2002 near the Washington State University Campus at Pullman, WA $\left(46^{\circ} 43^{\prime} 40^{\prime \prime} \mathrm{N}, 117^{\circ} 11^{\prime} \mathrm{W}\right.$, and elevation at $\left.716 \mathrm{~m}\right)$. Three isolates of $P$. infestans were used. Isolate $110 \mathrm{~B}$ was isolated from potato foliage collected in western Washington in 1997, and was of the US-11 clonal lineage (17). Isolates 701 and 502 were isolated from potato foliage collected in southeastern and central Washington, respectively, and were both of the US-8 clonal lineage (17). Isolate 701 was isolated in 2001 and isolate 502 in 2002. Isolates were maintained on excised leaflets of cv. Ranger Russet in an incubator at $15^{\circ} \mathrm{C}$ with an 18 -h photoperiod. Cultures were transferred to fresh leaflets every 9 to 10 days. Potato leaves were obtained from plants grown in a greenhouse. Survival of isolates 701 and 110B was assessed in July and October 2001. Survival of isolates 110B and 502 was assessed in July 2002.

Sporangia production. Sporangia of each isolate were rinsed from lesions on leaflets of cv. Ranger Russet into beakers with distilled water to a concentration of 50,000 to 65,000 sporangia per $\mathrm{ml}$. A hemacytometer was used to determine concentrations of all spore suspensions in this study. Suspensions were placed at 
$4^{\circ} \mathrm{C}$ for $2 \mathrm{~h}$ to induce zoospore formation. A $1-\mathrm{cm}^{2}$ Whatman No. 2 filter paper square was then immersed in the respective spore suspensions and placed in the center of the adaxial surface on a freshly cut leaflet of cv. Ranger Russet. About 25 leaflets were inoculated per isolate. Inoculated leaflets were then placed with the adaxial surface downward on a fiberglass screen over moistened paper towels in separate plastic containers $(35$ by 25 by $12.5 \mathrm{~cm})$. Leaflets were incubated at $15^{\circ} \mathrm{C}$ for 6 days and the sporangia that formed from 2-day-old lesions were rinsed from the leaflets with distilled water. Sporangia suspensions of each isolate were divided equally into two beakers. The sporangia suspension in one beaker was chilled for $2 \mathrm{~h}$ at $10^{\circ} \mathrm{C}$, and the other was maintained at $23^{\circ} \mathrm{C}$ for the same time period.

Spore suspensions were immediately taken to the study site with a transport time of $3 \mathrm{~min}$, and 100,000 sporangia were added to glass petri dishes with a 5-ml pipet. The Pyrex deep petri dishes measured $8.75-\mathrm{cm}$ diameter by $1.9 \mathrm{~cm}$ deep and had previously been buried to the upper rim in a sandy soil. The amount of the suspension added to the petri dishes for all the survival experiments ranged between 1 to $3 \mathrm{ml}$ depending on the concentration of the suspension. The final concentration of sporangia in each petri dish was 769 sporangia per $\mathrm{ml}$ of water. The remaining contents of the chilled and nonchilled spore suspensions of the two isolates used in each trial were returned to the lab and maintained at $23^{\circ} \mathrm{C}$. Water volumes in the petri dishes were maintained throughout the duration of each trial near the upper rim by filling the dishes with distilled water approximately every $4 \mathrm{~h}$ during daylight. There was limited evaporation during the night hours, so petri dishes were filled after sunset and early in the morning.

Treatments and experimental setup. Petri dishes with sporangia suspensions of a US-8 or US-11 isolate were either shaded by placing them beneath a piece of plywood $(2.4 \mathrm{~m}$ by $1.2 \mathrm{~m}$ by $1.25 \mathrm{~cm}$ ) held $30 \mathrm{~cm}$ above the ground or they were not shaded. Shaded and nonshaded spore suspensions were then arranged randomly with the following two factors: sporangia chilled at $10^{\circ} \mathrm{C}$ or held at $23^{\circ} \mathrm{C}$ for $2 \mathrm{~h}$ before water infestation and presence or absence of $15 \mathrm{~g}$ of a Quincy loamy fine sand added to the petri dishes. The chilled spore suspensions contained zoospores. Land containing Quincy loamy fine sand is commonly used to grow potatoes, and the soil for the experiments was obtained from native noncropped ground located near potato fields in central Washington. The soil formed a 2- to 3-mm-deep layer in the bottom of the petri dishes when settled. The plywood prevented the exposure of spore suspensions to direct sunlight at all times of the day. Each trial was arranged in a $2^{4}(2 \times 2 \times 2 \times 2)$ complete factorial design. All combinations of the US-8 and US-11 isolates, chilled or nonchilled sporangial suspensions, shaded or nonshaded, and presence or absence of soil were included to give a total of 16 treatments with four replicates of each treatment. Negative controls of soil in water with no spores added to the petri dishes were randomly arranged and replicated four times each in the shade and nonshade.

Survival assessment. Tubers of cv. Ranger Russet were taken from cold storage at 4 to $5^{\circ} \mathrm{C}$, washed thoroughly in running tap water, rinsed with distilled water, immersed in $96 \%$ ethanol, and then flamed with a propane burner. Tuber disks were aseptically cut to a thickness of $0.5 \mathrm{~cm}$ and a diameter of 4 to $5 \mathrm{~cm}$ with a knife. Individual disks were then placed in deep petri dishes $(9-\mathrm{cm}$ diameter by $1.5 \mathrm{~cm})$. The petri dishes contained a fiberglass screen over filter paper moistened with $3 \mathrm{ml}$ of distilled water. Petri dishes containing the tuber disks were placed in a clear plastic container (37.5 by 22.5 by $21.3 \mathrm{~cm}$ ) with moistened paper towels in the bottom and carried to the study site. Petri dishes with the tuber disks were labeled to correspond with petri dishes containing the spores at the study site.

Contents of each petri dish containing spores were stirred with a clean plastic rod until a homogenous suspension was formed. The petri dish was then filled to the rim with distilled water, and a 1-ml sample was extracted and evenly spread on the surface of a previously cut tuber disk. Petri dishes containing the inoculated tuber disks for each sampling period were returned to the clear plastic container and the lid was sealed. Tuber disks were then incubated at $15^{\circ} \mathrm{C}$ with an 18 -h photoperiod. The percentage of tuber surface area producing sporangiophores and sporangia was determined on tuber disks after 6 days incubation. Tuber slices with no sporulation by 6 days were further incubated and again observed at 12-days postinoculation, and those slices with sporulating surface area were given an index value of 1 , indicating sporulation between a trace to $5 \%$, which was a rare event. Tuber disks with no sporulating surface area after 12 days were incubated an additional 2 weeks and observed for sporulating surface area. The percentage of tuber surface area with sporulation was categorized into the following sporulation index: 0 , no sporulation; 1 , trace to $5 \% ; 2,6$ to $25 \% ; 3,26$ to $50 \%$; 4,51 to $75 \%$; and 5,76 to $100 \%$. A relative area under the survival curve (RAUSC) was calculated from these percentages for each spore suspension over time by adapting the equation used to calculate the area under the disease progress curve (42): RAUSC $=\Sigma\left[\left(y_{i}+y_{i+1}\right) / 2 \times\right.$ $\left(t_{i+1}-t_{i}\right)$ ], where $y_{i}$ is the highest percentage within a sporulation index range for a tuber disk at time $t_{i}$, in days, and $y_{i+1}$ is the highest percentage within a sporulation index range for a tuber disk at time $t_{i+1}$. For example, if a sporulation index value of 4 was given to a tuber disk at time $t_{i}$, a percentage of $75 \%$ was used to calculate the RAUSC.

Sampling for viable spores was conducted after exposures of 1 , $2,3,6,8,10,13,16,20,23,26$, and 29 days. The sample was taken on day 5 instead of day 6 in July 2002. Sampling continued until viable spores were not found in three consecutive sampling periods.

In addition, single tuber disks were inoculated with each of the four spore suspensions that were used originally to apply the chilled and nonchilled inoculum of both the US-8 and US-11 isolates. These served as positive controls. In addition to the sample days previously mentioned, these spore suspensions were sampled every 3 days beyond day 29 to determine the duration of survival.

Determination of spore type. The percentage of sporangia that germinated indirectly was determined for each spore suspension used to infest the water contained in the petri dishes in the field immediately following the water infestation. The first 1,000 sporangia observed under a light microscope were counted, and the numbers of empty (no cytoplasm) and full (cytoplasm present) sporangia were noted. Empty sporangia were considered indicative of indirect germination (11). Zoospores were observed for all chilled treatments under a microscope.

Climatological measurements. Total solar irradiance (SI) in watts per square meter $\left(\mathrm{W} \mathrm{m}^{-2}\right)$ was measured every $15 \mathrm{~min}$ in the shade and nonshade by two pyranometers (200SA, Li-Cor, Lincoln, NE) placed horizontally at ground level within $12 \mathrm{~cm}$ of the petri dishes. A daily mean SI value was calculated from the SI values during the time when the spore suspensions were nonshaded. Water temperatures were measured in the shade and direct sunlight at 15-min intervals with a Model 450 Watch Dog Data Logger (Spectrum Technologies, Plainfield, IL). Daily sky conditions were recorded every hour by an Automated Surface Observing System at the Pullman airport, located $3 \mathrm{~km}$ from the research site.

Tuber disk bioassay to quantify spore survival. Two experiments were conducted to justify the use of tuber disks to determine the quantity of surviving spores over set sampling periods. In the first experiment, sporangia from 2-day-old sporulating lesions on excised Ranger Russet potato leaflets of isolate 502 were rinsed with distilled water into a $100-\mathrm{ml}$ beaker. The concentration of the sporangia was 48,000 and 66,000 sporangia per ml of distilled water for the two trials. Serial dilutions were performed using two sets of seven 250-ml beakers. The first beaker in each set contained a $130-\mathrm{ml}$ suspension of sporangia at a concentration 
of 769 sporangia per $\mathrm{ml}$. The spore concentration and volume of water in the beakers was the same as in an individual petri dish used during the survival study. A serial dilution series was performed until the concentration of the suspension in the final beaker was 1 sporangia per $\mathrm{ml}$ of distilled water. The concentrations in the beakers for the serial dilutions in each set were 769, $256,85,28,9,3$, and 1 sporangia per $\mathrm{ml}$. One set of seven beakers was chilled at $10^{\circ} \mathrm{C}$ for $2 \mathrm{~h}$ to induce zoospore formation, and the other set was maintained at room temperature at $23^{\circ} \mathrm{C}$ during the same time period. The suspensions for each dilution were then stirred for $1.5 \mathrm{~min}$ to homogenize the contents and five 1-ml samples were taken from each dilution and temperature combination and put onto five tuber disks contained in separate petri dishes. The tuber disks in the petri dishes were prepared following the same procedure described previously. The petri dishes were randomly arranged in an 18.5-liter plastic container and put at $15^{\circ} \mathrm{C}$ with an 18 -h light cycle. The percentage of tuber surface area producing sporangiophores and sporangia was determined on the tuber disks after incubation for 6 and 12 days to give an indication of the quantity of propagules that survived. Tuber disks with no observed sporulation after 12 days of incubation did not sporulate when incubated for an additional 14 days. The percentage of tuber surface area with sporulation was categorized by the sporulation index previously described.

In the second experiment, the same procedure as that described for the first experiment was followed, except sporangia of isolates 502 and 110B were rinsed with distilled water into separate 100-ml beakers and a given volume of each suspension was added to distilled water in 1,000-ml flasks to obtain 900-ml spore suspensions of each isolate at a concentration of 769 sporangia per $\mathrm{ml}$. Serial dilution series were performed for each suspension of each isolate using 1,000-ml flasks by removing $300 \mathrm{ml}$ of the spore suspension at a concentration of 769 sporangia per $\mathrm{ml}$ of water and adding it to a flask containing $600 \mathrm{ml}$ of distilled water. The concentrations in the flasks for the serial dilutions were the same as in the first experiment. Four sets of seven Pyrex deep petri dishes were filled with the different dilutions for each isolate. Each set contained one petri dish filled with $100 \mathrm{ml}$ of each of the seven dilutions. The petri dishes in two of the four sets each contained $15 \mathrm{~g}$ of a Quincy loamy fine sand and the petri dishes in the other two sets did not contain soil. Two sets of petri dishes for each isolate, one with soil and one without, were chilled for $2 \mathrm{~h}$ at $10^{\circ} \mathrm{C}$ to induce zoospore formation, and the remaining sets were maintained at room temperature at $23^{\circ} \mathrm{C}$ during the same time period. The four sets of chilled plates, two from each isolate, were placed side by side on a table in a dark room with the nonchilled plates after the 2 -h chill period. The petri dishes were maintained near a $100-\mathrm{ml}$ fill-line mark. Spore survival was assessed 1 and 7 days following the addition of the spores to water. To assess survival, the petri dishes were filled to the $100-\mathrm{ml}$ fillline, and the contents within a petri dish were stirred for $1 \mathrm{~min}$ and five 1-ml samples were taken from each petri dish and put onto five tuber disks contained in separate petri dishes. The petri dishes were prepared as previously described. The petri dishes for each isolate were randomly arranged in separate plastic containers $(38.5$ by $52 \mathrm{~cm})$ lined with moistened paper towels and put at $15^{\circ} \mathrm{C}$ with an 18 -h light cycle. The survival of the spores in the petri dishes was assessed after incubation for 6 and 12 days as described previously. The experiment was repeated.

Statistical methods. A spore suspension in an individual petri dish was considered an experimental unit. Data for duration of survival were analyzed by analysis of variance (ANOVA) using Proc GLM procedure in SAS (SAS Institute, Cary, NC). The Shapiro-Wilk statistic was used to test for normality. The RAUSC data were analyzed by ANOVA using Proc rank procedure in SAS followed by Proc GLM. The relationship of percent sporulating surface area on tuber disks (dependent variable) and concentration of spores applied to tuber disks (independent variable) was investigated using an ordinal logistic regression procedure of MINITAB (Minitab Inc., University Park, PA) (1) and a Proc REG procedure in SAS using a Log+1 transformation of the concentration.

\section{RESULTS}

Spore suspensions of the US- 8 isolates chilled for $2 \mathrm{~h}$ at $10^{\circ} \mathrm{C}$ in July 2001, October 2001, and July 2002 had 57, 65, and 49\% empty sporangia, respectively. Spore suspensions of the US-11 isolate chilled for $2 \mathrm{~h}$ at $10^{\circ} \mathrm{C}$ for the same dates had 56,70 , and $63 \%$ empty sporangia, respectively. The percentage of empty sporangia for nonchilled inoculum in July 2001, October 2001, and July 2002 of the US-8 isolate was 1,42 , and $0.4 \%$, respectively. The percentage of empty sporangia for nonchilled inoculum in July 2001, October 2001, and July 2002 of the US-11 isolate was 2,46 , and $5.0 \%$, respectively. The water temperature for the nonchilled suspensions used to infest the water in the petri dishes in July 2001 and July 2002 was 16 and $11^{\circ} \mathrm{C}$, respectively, and zoospore formation was not observed. The water temperature during the water infestation period in October 2001 was $5^{\circ} \mathrm{C}$, which induced zoospore formation in the nonchilled sporangia.

Climatological data. Daily mean pyranometer values for the nonshaded treatments ranged from 4 to $1,031 \mathrm{~W} \mathrm{~m}^{-2}$ for the July trials and 12 to $661 \mathrm{~W} \mathrm{~m}^{-2}$ in October (Table 1). Pyranometer readings for the shaded treatments did not exceed $8 \mathrm{~W} \mathrm{~m}^{-2}$, and the highest mean value observed for a single day was $5.0 \pm 1.2 \mathrm{~W} \mathrm{~m}^{-2}$ in July 2002. The daily mean solar radiation exposures during the survival period in July 2001, July 2002, and October 2001 were 588,674 , and $318 \mathrm{~W} \mathrm{~m}^{-2}$, respectively. The photoperiod in July was $11.5 \mathrm{~h}$ and it was $7.5 \mathrm{~h}$ in October. Sky conditions were mostly clear for the first 4 days of each trial, but there was a significantly greater amount of cloud cover in October than in the July trials (Table 1). Water temperatures in the shade ranged from

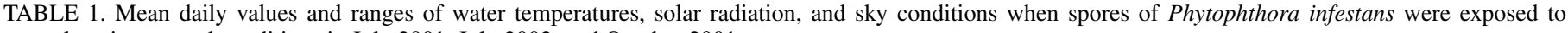
natural environmental conditions in July 2001, July 2002, and October 2001

\begin{tabular}{|c|c|c|c|c|c|c|}
\hline \multirow[b]{2}{*}{ Environmental factors } & \multicolumn{2}{|c|}{ July 2001} & \multicolumn{2}{|c|}{ July 2002} & \multicolumn{2}{|c|}{ October 2001} \\
\hline & Mean $\pm \mathrm{SE}$ & Range & Mean $\pm \mathrm{SE}$ & Range & Mean $\pm \mathrm{SE}$ & Range \\
\hline Day ${ }^{\mathrm{a}}$ water temp. $\left({ }^{\circ} \mathrm{C}\right)$, nonshaded ${ }^{\mathrm{b}}$ & $24.1 \pm 2.4$ & $10-36$ & $27.5 \pm 2.5$ & $9-42$ & $11.4 \pm 2.9$ & $1-27$ \\
\hline Day water temp. $\left({ }^{\circ} \mathrm{C}\right)$, shaded ${ }^{\mathrm{c}}$ & $17.3 \pm 1.9$ & $11-24$ & $20.5 \pm 2.2$ & $9-29$ & $8.7 \pm 1.5$ & $3-16$ \\
\hline Solar radiation, nonshaded $\left(\mathrm{W} \mathrm{m}^{-2}\right)$ & $588 \pm 111$ & $27-1,031$ & $674 \pm 83$ & $4-1,015$ & $318 \pm 137$ & $12-661$ \\
\hline Sky condition ${ }^{\mathrm{d}}$ & $0.91 \pm 1.1$ & $0-3.7$ & $0.15 \pm 0.4$ & $0-1.5$ & $1.7 \pm 1.4$ & $0-4.0$ \\
\hline Night water temp. $\left({ }^{\circ} \mathrm{C}\right)$, nonshaded & $15.3 \pm 1.5$ & $10-19$ & $17.6 \pm 1.8$ & $10-24$ & $6.2 \pm 1.7$ & $0.1-14$ \\
\hline Night water temp. $\left({ }^{\circ} \mathrm{C}\right)$, shaded & $16.6 \pm 1.5$ & $11-19$ & $17.5 \pm 1.8$ & $9-23$ & $7.0 \pm 1.1$ & $2-13$ \\
\hline
\end{tabular}

a Day was measured from 4:30 a.m. to 9:00 p.m. for July trials and 6:45 a.m. to 6:45 p.m. in October.

b Petri dishes not covered.

c Petri dishes covered by a plywood barrier placed $30 \mathrm{~cm}$ above the plates.

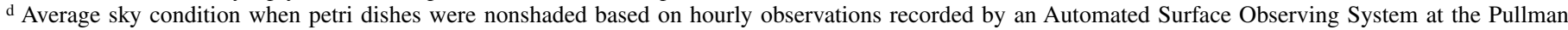
Moscow Regional Airport located $3 \mathrm{~km}$ from the study site: 0 to $0.4=0 / 8$ clear sky, 0.5 to $1.4=1 / 8$ to $2 / 8$ sky cover, 1.5 to $2.4=3 / 8$ to $4 / 8$ sky cover, 2.5 to 3.4 $=5 / 8$ to $7 / 8$ sky cover, and 3.5 to $4.0=8 / 8$ sky cover. 
9 to $29^{\circ} \mathrm{C}$ for the July trials and 3 to $16^{\circ} \mathrm{C}$ in October (Table 1). Water temperatures in the nonshaded treatments ranged from 9 to $42^{\circ} \mathrm{C}$ for the July trials and 1 to $27^{\circ} \mathrm{C}$ in October.

Survival trials. Maximum duration of spore survival for July 2001, July 2002, and October 2001 was 13 to 16,10 to 13 , and 16 to 20 days, respectively (Table 2). Maximum spore survival of the original inoculum stored at $23^{\circ} \mathrm{C}$ in the lab was 46 to 49,60 to 63 , and 29 to 32 days for July 2001, October 2001, and July 2002, respectively.

Survival of shaded spores was significantly longer $(P=0.001)$ than survival of nonshaded spores for all three trials. Shaded spores in July 2001, July 2002, and October 2001 had a mean survival of 8.4, 6.2, and 9.3 days, respectively, and nonshaded spores had a mean survival of 2.2, 1.2, and 5.8 days for July 2001, July 2002, and October 2001, respectively.

Survival was significantly longer $(P=0.0001)$ when soil was present than when soil was absent in the spore suspensions. Spores survived for 6.7, 4.6, and 10.4 days in July 2001, July
2002, and October 2001, respectively, when soil was added to the suspensions; and spores survived for 3.8, 2.9, and 4.6 days in July 2001, July 2002, and October 2001, respectively, in suspensions without soil. Spore suspensions containing soil survived 1.7 to 5.8 days longer than spore suspensions without soil (Table 2).

Length of spore survival did not differ significantly $(P>0.05)$ for chilled and nonchilled sporangia, or for US-8 and US-11 isolates in July 2001 and July 2002. However, there was a significant interaction between isolate and soil $(P=0.02)$ in October 2001 . The US- 8 isolate survived significantly longer than the US-11 isolate when soil was not present. The US-8 and US-11 isolates survived for 5.8 and 3.5 days, respectively. All tuber disks were negative for sporulation of $P$. infestans in treatments acting as negative controls.

RAUSC. Significantly more spores survived in the shade $(P=$ 0.001 ) than in those that were nonshaded in all three trials (Table 3 ). RAUSC values in the shaded treatments were 301,315 , and 105 in July 2001, July 2002, and October 2001, respectively.

TABLE 2. Mean number of days and range that sporangia and zoospores of Phytophthora infestans survived under natural environmental conditions in July 2001, July 2002, and October 2001, when sporangia water suspensions of either US-8 or US-11 were shaded or nonshaded ${ }^{\mathrm{a}}$

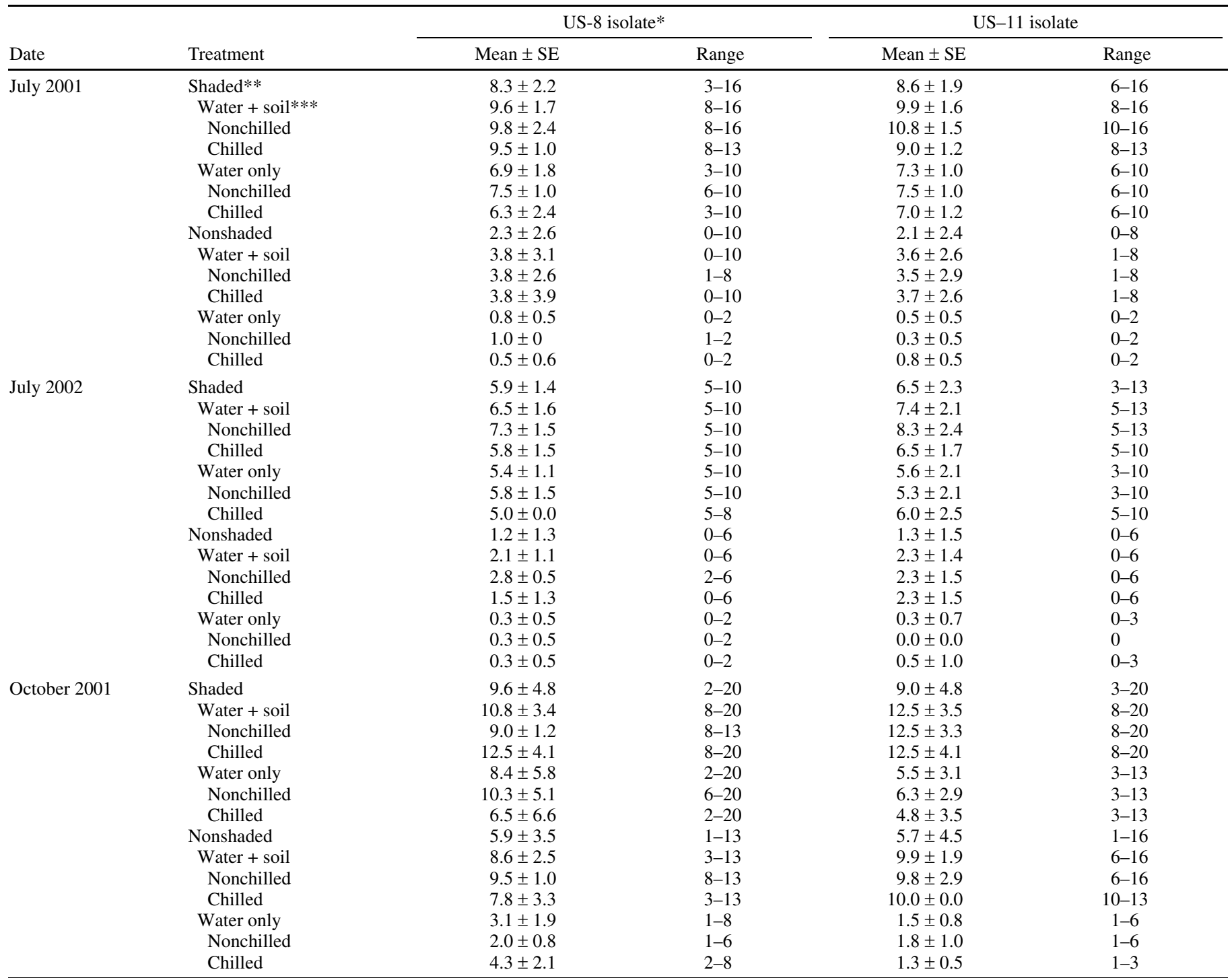

\footnotetext{
${ }^{a}$ Shaded and nonshaded spore suspensions were arranged randomly with the following factors: sporangia chilled at $10^{\circ} \mathrm{C}$ or nonchilled at $23^{\circ} \mathrm{C}$ for $2 \mathrm{~h}$ before water infestation, and presence or absence of $15 \mathrm{~g}$ of a sandy soil added to the petri dishes. * Indicates there were no significant differences $(P>0.05)$ between the isolates in July 2001 and July 2002 and no significant interactions among the treatments. There was a significant difference between the isolates in October 2001; US-11 water only was significantly different from the US-8 water only. ** Indicates that shaded treatments survived significantly longer $(P=0.0001)$ than nonshaded treatments, 8.4 to 2.2 days, 6.2 to 1.2 days, and 9.3 and 5.8 days, respectively, in July 2001, July 2002 and October 2001 . *** Indicates that water + soil treatments survived significantly longer $(P=0.0001)$ than those with water only, 6.7 and 3.8 days, 4.6 and 2.9 days, and 10.4 and 4.6 days, respectively, in July 2001, July 2002, and October 2001.
} 
RAUSC values in the nonshaded treatments were 30,18 , and 53 in July 2001, July 2002, and October 2001, respectively.

Significantly more spores survived over extended periods when soil was present than when soil was not present $(P=0.0001)$

TABLE 3. Mean relative area under the survival curve (RAUSC ${ }^{a}$ ) of sporangia and zoospore of Phytophthora infestans under natural environmental conditions in July 2001, July 2002, and October 2001, when sporangia water suspensions of US-8 or US-11 were shaded or nonshaded ${ }^{\mathrm{b}}$

\begin{tabular}{|c|c|c|c|}
\hline \multirow[b]{2}{*}{ Date } & \multirow[b]{2}{*}{ Treatment } & \multirow{2}{*}{$\frac{\text { US-8 isolate* }}{\text { Mean } \pm \text { SE }}$} & \multirow{2}{*}{$\frac{\text { US-11 isolate }}{\text { Mean } \pm \text { SE }}$} \\
\hline & & & \\
\hline \multirow[t]{14}{*}{ July 2001} & Shaded** & $301 \pm 143$ & $357 \pm 133$ \\
\hline & Water + soil $* * *$ & $406 \pm 98$ & $458 \pm 87$ \\
\hline & Nonchilled $* * * *$ & $447 \pm 124$ & $489 \pm 115$ \\
\hline & Chilled & $366 \pm 51$ & $427 \pm 44$ \\
\hline & Water only & $196 \pm 94$ & $256 \pm 82$ \\
\hline & Nonchilled & $246 \pm 98$ & $318 \pm 73$ \\
\hline & Chilled & $146 \pm 65$ & $195 \pm 21$ \\
\hline & Nonshaded & $30 \pm 39$ & $35 \pm 43$ \\
\hline & Water + soil & $52 \pm 46$ & $66 \pm 42$ \\
\hline & Nonchilled & $64 \pm 47$ & $78 \pm 49$ \\
\hline & Chilled & $40 \pm 48$ & $54 \pm 36$ \\
\hline & Water only & $8 \pm 6$ & $5 \pm 6$ \\
\hline & Nonchilled & $13 \pm 0$ & $3 \pm 6$ \\
\hline & Chilled & $4 \pm 6$ & $7 \pm 7$ \\
\hline \multirow[t]{14}{*}{ July 2002} & Shaded** & $315 \pm 135$ & $224 \pm 136$ \\
\hline & Water + soil $* * *$ & $406 \pm 111$ & $291 \pm 143$ \\
\hline & Nonchilled**** & $466 \pm 40$ & $351 \pm 166$ \\
\hline & Chilled & $347 \pm 133$ & $230 \pm 103$ \\
\hline & Water only & $225 \pm 89$ & $157 \pm 94$ \\
\hline & Nonchilled & $272 \pm 99$ & $223 \pm 70$ \\
\hline & Chilled & $178 \pm 51$ & $92 \pm 68$ \\
\hline & Nonshaded & $18 \pm 28$ & $15 \pm 25$ \\
\hline & Water + soil & $35 \pm 31$ & $29 \pm 30$ \\
\hline & Nonchilled & $49 \pm 30$ & $29 \pm 33$ \\
\hline & Chilled & $21 \pm 29$ & $29 \pm 33$ \\
\hline & Water only & $1 \pm 1$ & $1 \pm 3$ \\
\hline & Nonchilled & $1 \pm 1$ & $0 \pm 0$ \\
\hline & Chilled & $1 \pm 1$ & $2 \pm 4$ \\
\hline \multirow{14}{*}{ October 2001} & Shaded** & $105 \pm 48$ & $154 \pm 129$ \\
\hline & Water + soil $* * *$ & $131 \pm 53$ & $248 \pm 121$ \\
\hline & Nonchilled $* * * *$ & $105 \pm 59$ & $313 \pm 116$ \\
\hline & Chilled & $157 \pm 36$ & $183 \pm 98$ \\
\hline & Water only & $79 \pm 23$ & $61 \pm 31$ \\
\hline & Nonchilled & $81 \pm 18$ & $73 \pm 25$ \\
\hline & Chilled & $78 \pm 30$ & $49 \pm 35$ \\
\hline & Nonshaded & $53 \pm 33$ & $42 \pm 36$ \\
\hline & Water + soil & $75 \pm 29$ & $74 \pm 17$ \\
\hline & Nonchilled & $86 \pm 12$ & $76 \pm 17$ \\
\hline & Chilled & $65 \pm 39$ & $72 \pm 19$ \\
\hline & Water only & $30 \pm 18$ & $9 \pm 7$ \\
\hline & Nonchilled & $24 \pm 19$ & $13 \pm 7$ \\
\hline & Chilled & $36 \pm 16$ & $6 \pm 5$ \\
\hline
\end{tabular}

a RAUSC $=\Sigma\left[\left(y_{i}+y_{i+1}\right) / 2 \times\left(t_{i+1}-t_{i}\right)\right]$, where $y_{i}$ is the highest percentage within a sporulation index range for a tuber disk at time $t_{i}$, in days, and $y_{i+1}$ is the highest percentage within a sporulation index range for a tuber disk at time $t_{i+1}$. Index values range from 0 to $5 . *=$ Mean RAUSC of the isolates was not significantly different in July 2001 and October 2001; however, the mean RAUSC for the US-8 isolate in July 2002 was significantly different $(P=0.0245)$ from the US-11, 167 to 119 , respectively. There were no significant interactions among treatments for each date $(P>0.05)$. ** $=$ Mean RAUSC values of shaded treatments were significantly different from nonshaded treatments, 329 and 33, 270 and 16, and 130 and 48, respectively, for July 2001, July 2002, and October $2001(P=0.0001)$. *** $=$ Mean RAUSC values of treatments with soil were significantly different from those without soil, 246 and 116, 190 and 96, and 132 and 45, respectively $(P=0.0001){ }^{* * * *}=$ Mean RAUSC values of chilled treatments were significantly different from nonchilled in July 2001 and July 2002, 207 and 155 and 174 and 112 , respectively $(P=0.0001)$. Mean RAUSC values of chilled treatments were not significantly different for nonchilled treatments in October $2001(P>0.05)$.

b Shaded and nonshaded spore suspensions were arranged randomly with the following factors: sporangia chilled at $10^{\circ} \mathrm{C}$ or nonchilled at $23^{\circ} \mathrm{C}$ for $2 \mathrm{~h}$ before water infestation, and presence or absence of $15 \mathrm{~g}$ of a sandy soil added to the petri dishes.
(Table 3). Duration of survival was not significantly affected by a chill period but the number of propagules surviving for extended periods of time was significantly decreased by a chill period (Table 3). Nonchilled sporangia had RAUSC values of 207, 174, and 96 in July 2001, July 2002, and October 2001, respectively, and chilled sporangia had RAUSC values of 155, 112, and 80 in July 2001, July 2002, and October 2001, respectively. The US-11 isolate and US-8 isolate 701 did not differ significantly $(P>$ $0.05)$. However, there were significant differences between the US-11 isolate and the US-8 isolate 502 in RAUSC values, 119 versus 167 , respectively $(P=0.0245)$ (Table 3$)$. An example of the shape of the curves for the RAUSC for each treatment for the July 2001 survival study are presented in Figure 1 . Curves for the October 2001 and July 2002 survival studies were similar. Curves indicate a decrease over time in amount of sporulation on tuber disks for all treatments.

Tuber disk bioassay to quantify spore survival. Concentration of sporangia per $\mathrm{ml}$ of water was a significant predictor $(P=$ 0.0001 ) of mean sporulation index value (Fig. 2) and amount of
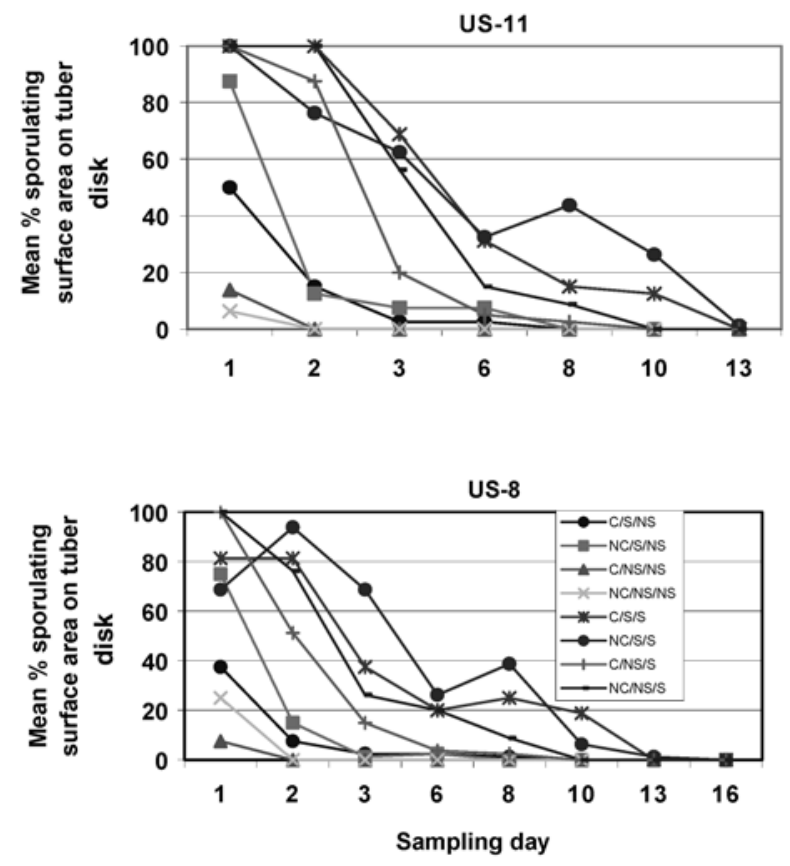

Fig. 1. Relative areas under the survival curve for a US-8 and US-11 isolate of Phytophthora infestans in July 2001 when the mean value of the four replicates per sampling date of each treatment were graphed. Letters in legend followed by a back slash signify the following: $\mathrm{C}=$ sporangia chilled for $2 \mathrm{~h}$ or $\mathrm{NC}=$ sporangia nonchilled $/ \mathrm{S}=$ soil present in petri dish or $\mathrm{NS}=$ no soil in petri dish $/ \mathrm{S}=$ petri dish shaded or NS = petri dish nonshaded.

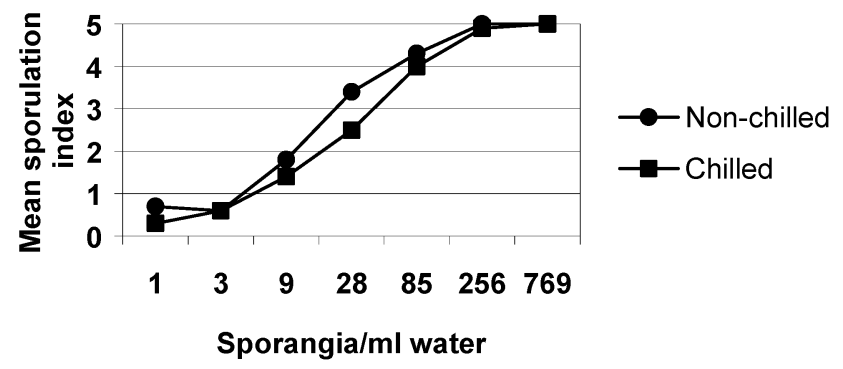

Fig. 2. Effects of a chill period and concentration of sporangia and zoospores on the sporulating surface area of tuber disks when $1 \mathrm{ml}$ of inoculum was applied ( $n=10$ tuber disks per concentration) and tuber disks were incubated for 6 days at $15^{\circ} \mathrm{C}$ with an 18-h light period. The amount of sporulation was grouped into six categories: 0 , no sporulation; 1 , trace to $5 \% ; 2,6$ to $25 \% ; 3$, 26 to $50 \% ; 4,51$ to $75 \%$; and 5,76 to $100 \%$. Concentration of sporangia per milliliter of water was a significant predictor $(P=0.0001)$ of mean sporulation index value using ordinal logistic regression. 
sporulating tuber disk surface area (Table 4). Sporulation area increased as concentration of spores used to inoculate tuber disks increased during sampling periods (Figs. 2 and 3). Data for the two serial dilution trials for the first experiment were combined because there were no significant differences found between the two trials using an $F$ test (Fig. 2). The two trials for the second serial dilution experiment were not combined but had similar results; only the data from the first trial is shown (Fig. 3; Table 4). Nonchilled sporangia had a significantly greater overall mean sporulation index value than sporangia that were chilled $(P=$ 0.012) (Fig. 2). Correlation coefficients for the relationship between inoculum concentration and amount of sporulation on tuber disks were more positively correlated for the US-8 isolate than for the US-11 isolate for most treatments (Table 4).

\section{DISCUSSION}

Spores of $P$. infestans survived in surface water between 14 to 21 days under ambient conditions simulating a surface water environment that would be found in commercial potato fields. This information indicates that spores of $P$. infestans have the capability of surviving in water for extended periods of time after being

TABLE 4. Adjusted $R^{2}$ values for the relationship between increasing sporangia concentration $(1,3,9,28,85,256$, and 769 sporangia per $\mathrm{ml}$ of water) and amount of sporulating surface area on tuber disks when spore suspensions containing sporangia of US-8 or US-11 isolate of Phytophthora infestans were chilled at $10^{\circ} \mathrm{C}$ for $2 \mathrm{~h}$ or nonchilled and suspensions contained either the presence or absence of soil ${ }^{\mathrm{a}}$

\begin{tabular}{lcccc}
\hline & \multicolumn{4}{c}{ Treatment } \\
\cline { 2 - 5 } $\begin{array}{l}\text { Isolate/sample } \\
\text { time }\end{array}$ & $\begin{array}{c}\text { Chilled }+ \\
\text { soil }\end{array}$ & $\begin{array}{c}\text { Nonchilled }+ \\
\text { soil }\end{array}$ & $\begin{array}{c}\text { Chilled }+ \\
\text { no soil }\end{array}$ & $\begin{array}{c}\text { Nonchilled + } \\
\text { no soil }\end{array}$ \\
\hline US-8/day 1 & 0.8738 & 0.8485 & 0.7774 & 0.8221 \\
US-8/day 7 & 0.7663 & 0.8048 & 0.5071 & 0.3710 \\
US-11/day 1 & 0.5281 & 0.6879 & 0.7136 & 0.4301 \\
US-11/day 7 & 0.5445 & 0.6112 & 0.5162 & 0.3778 \\
\hline
\end{tabular}

a $P$ values for the model statements of all treatments were $P=0.0001$. One milliliter of inoculum was applied ( $n=5$ tuber disks per concentration and sampling period) to tuber disks 1 and 7 days after sporangia were placed in water.
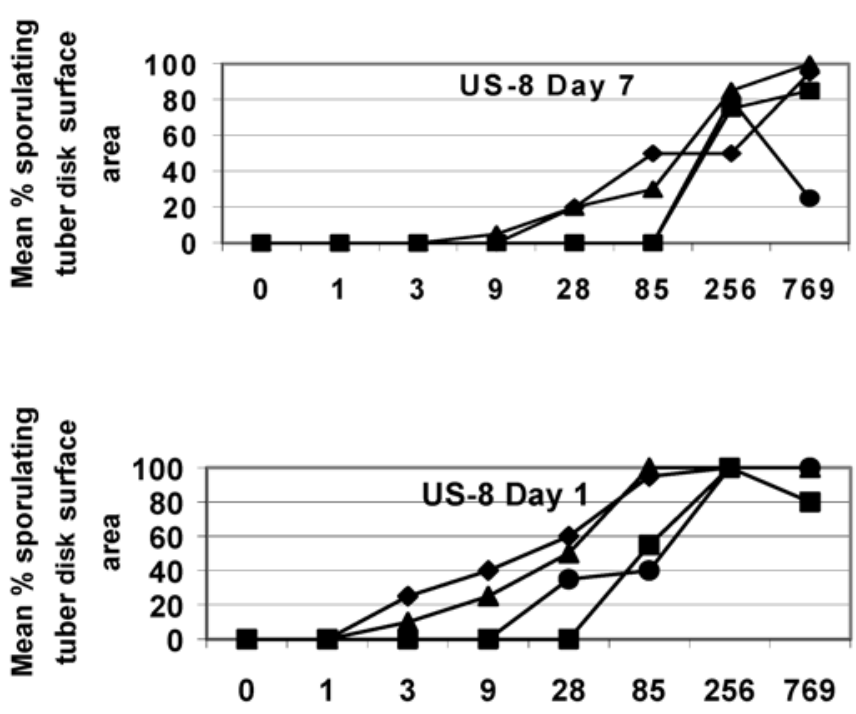

released from sporangiophores on sporulating potato tissue. The center pivot in overhead center pivot irrigation makes a $360^{\circ}$ rotation every 18 to $24 \mathrm{~h}$ during hot weather in the Columbia Basin. Spores surviving in surface water in the wheel tracks during a 3 -week period could be dispersed approximately 54 times by the wheels, providing opportunities for surviving spores to be possibly deposited on the top and under surfaces of adjacent potato plant tissue. Incidence of late blight tuber rot is often high in wet areas of fields and is also likely influenced by survival of spores in surface water (22). Irrigation water is sometimes reused and spores could be transported to neighboring fields through infested water.

The RAUSC provided a good relative determination of the quantity of surviving spores between treatments over extended periods of time. The amount of sporulating tuber surface area was directly related to the quantity of spores that survived on the surface of the tuber disk based on the results from the serial dilution tests.

This study supports previous research indicating UVR as a paramount factor governing survival of $P$. infestans spores. UVR, particularly UVB radiation in the 280 to $310 \mathrm{~nm}$ wavelength, is detrimental to biological organisms (13) including $P$. infestans $(34,43)$. Sporangia of $P$. infestans are hyaline, making them especially vulnerable to $\operatorname{UVR}(6,16)$. The factors limiting the lethal effects of UVR on spore survival during the trials ranked in order of importance were presence of water, solar radiation intensity, presence of soil, chill period, and genotype.

Sporangia of $P$. infestans exposed to the atmosphere during cloudy conditions rarely survive for more than 3 to $4 \mathrm{~h}$, and in direct sunlight survival is rare beyond $1 \mathrm{~h}(15,34,43)$. Petri dishes in direct sunlight containing only water extended the survival of spores up to 6 days. Water by itself may prolong the survival of spores by reducing UVR exposure. Solar UVR declines exponentially with water depth (9). Spores in surface water are also in a water-saturated environment and the relative humidity of the surrounding environment is no longer a factor affecting spore hydration.

A reduction in solar radiation intensity was likely the greatest factor prolonging duration of survival and number of spores that survived over extended periods in surface water. Solar radiation intensity was reduced by shade, cloudy atmospheric conditions,

\section{Sporangia/ml water}
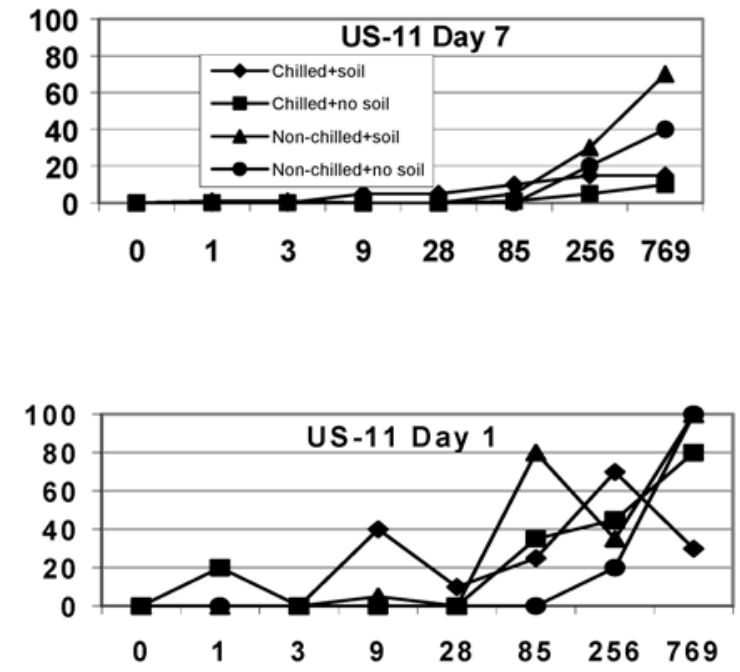

Fig. 3. Effects of a 2-h chill period, presence or absence of soil, clonal lineage of Phytophthora infestans, and concentration of sporangia and zoospores on the sporulating surface area of tuber disks when $1 \mathrm{ml}$ of inoculum was applied ( $n=5$ tuber disks per concentration and sampling period) to tuber disks 1 and 7 days after sporangia were placed in water. Sporangia were maintained in deep glass petri dishes in the dark at $23^{\circ} \mathrm{C}$. Table 4 provides information to obtain the adjust $R^{2}$ values for the treatments. 
reduced SI intensity, and shorter photoperiod due to time of year. All of these factors likely prolonged the survival of $P$. infestans spores in the three trials.

Survival of shaded spores was significantly greater than nonshaded spores in all three trials. The plant canopy in a potato field also would provide the shade that favors spore survival of up to 3 weeks in surface water. The survival of spores in both the shaded and nonshaded treatments was significantly greater in October than in July. Photoperiods were longer, SI intensities were higher, and atmospheric conditions were less cloudy in July 2001 and July 2002 than in October 2001. The significant differences in UVR exposure between the October and July trials (Table 1) would be a major contributing factor to the longer survival of spores in October (Table 2).

The presence of soil in the water significantly increased the length of spore survival and the number of spores surviving over extended periods in both nonshaded and shaded treatments. Soil microorganisms and metal ions have been implicated in reducing the survival of $P$. infestans; however, soil may protect sporangia from UVR, which may be a more important factor under our conditions than metal ions and microorganisms $(4,46)$. The soil used in the trials and soil from potato fields throughout the Columbia Basin are neutral to alkaline, which reduces the concentration of free metal ions that would be detrimental to the spores (4).

Zoospores are less resistant to detrimental environments than sporangia $(36,46)$ and the lower ability of zoospores to survive would explain why the chilled treatments had significantly fewer spores surviving over extended periods. Ironically, cool temperatures favoring development of zoospores appear to reduce the likelihood of $P$. infestans survival if no host is present for infection to take place. However, all chilled sporangia do not produce zoospores. Among the six chilled suspensions for the three trials, 30 to $50 \%$ of the sporangia did not form zoospores. Sporangia that do not form zoospores under conditions favorable for zoospore formation may be specially adapted for survival.

Environmental conditions in October favored formation of zoospores for all treatments making it impossible to test differences between chilled and nonchilled sporangia. Even though ambient temperatures were cool enough to induce zoospore formation, the spores of $P$. infestans still survived for longer periods of time in October than in either of the July trials; however, the number of spores surviving over extended periods in October were significantly less than both July trials based on the area under the sporulation curve values (Table 3). Reduced spore survival in October is most likely due to the formation of zoospores, which are more sensitive to UVR than are sporangia (30-32,44).

Other factors besides UVR exposure may have affected the length of spore survival in October. Temperatures for the October trial were cooler than the July trials. The difference between the mean daytime temperatures for the October and the July trials was 12.7 and $16.1^{\circ} \mathrm{C}$ for July 2001 and July 2002, respectively. Metabolic rates decrease at lower temperatures. A $10^{\circ} \mathrm{C}$ increase in temperature doubles the metabolic rate of organisms (40). Each spore contains a defined amount of reserved energy. The lower temperatures in October would decrease the metabolic rate and better conserve the finite amount of energy each spore contains, allowing them to survive for longer periods of time. Shaded treatments also had cooler water temperatures than nonshaded treatments (Table 1), which may have significantly contributed to the longer spore survival under shaded conditions.

The US-8 clonal lineage has dominated the populations in the Columbia Basin (33). The US-8 isolates used in this study did not significantly differ from the US-11 isolate in duration of survival. However, a larger number of sporangia of US-8 isolate 502 survived for extended periods of time compared with that of US-11 isolate 110B. Greater quantities of spores surviving would be advantageous in maintaining a higher population in a potato-growing region. More US-8 and US-11 isolates need to be tested to determine if the spores of US-8 clonal lineage have a greater capacity to survive under natural environmental conditions than spores of the US-11 clonal lineage.

Survival of $P$. infestans propagules in this study was based on infection and sporulation on host tissue and not on germination on an artificial medium. Irradiated zoospores of $P$. infestans exposed to various dosages of artificial UVR germinated in previous studies, but normal growth did not continue beyond initial germination resulting in postgermination mortality $(30,32)$. Therefore, when assessing the effects of natural UVR on sporangia or zoospore survival, growth and sporulation on host tissue is a better indicator of survival than germination. Assessing survival based on germ tube or zoospore formation in an artificial medium may overestimate survival.

Biological organisms combat the deleterious effects of UVR with several repair mechanisms: photoreactivation, excision repair, postreplication repair, and SOS (extreme distress) repair (13). Photoreactivation has been demonstrated in zoospores of $P$. infestans and in conidia of several fungi $(14,32)$. This repair mechanism only takes place in visible light (330 to $600 \mathrm{~nm}$ ) and involves the removal of harmful pyrimidine dimers formed during UVR exposure. Exposing zoospores of $P$. infestans to visible light for $15 \mathrm{~min}$ after an artificial irradiation treatment was not sufficient time for photoreactivation repair of damaged DNA; however, the ability to germinate was restored with a 1-h exposure to visible light after irradiation (32). This phenomenon was attributed to the ability of the photoreactivation repair mechanisms within the zoospores to repair UV-damaged DNA. This capacity was important in restoring the ability of spores to both germinate and initiate infections when exposed to moderate levels of irradiation. The excision repair mechanism occurs only in the dark and involves enzymatic removal of mutated regions (13). Postreplication repair involves DNA synthesis to repair nucleotide gaps created when damaged DNA is replicated, and SOS repair permits replication of DNA across thymine dimer-damaged areas of DNA (13). A light-dark cycle was used in this study to assess the survival of $P$. infestans spores under conditions in which propagules were exposed to UVR. A light-dark cycle allowed for photoreactivation and excision repair mechanisms to repair DNA damage (14). Previously, sporangia have been incubated in the dark at $18^{\circ} \mathrm{C}$ in studies assessing the survival after certain exposures to natural UVR $(39,43)$. The survival of sporangia in these studies may have been limited because both visible light and darkness are needed for DNA repair mechanisms such as photoreactivation and excision repair to function properly (14).

Spores of $P$. infestans survived in field water for extended time periods in this study. Shade and soil in water increased the duration and number of spores surviving. Avoidance of conditions that promote surface water in potato fields would aid in managing late blight by decreasing the likelihood of survival and dispersal of spores, especially under the semiarid conditions that prevail in the Columbia Basin, WA.

\section{ACKNOWLEDGMENTS}

Funding for this study was provided by the Washington State Potato Commission. We thank L. M. Carris, D. A. Inglis, and R. E. Thornton for critically reading the manuscript and J. Miller for the use of his lab to complete additional experiments essential to publishing this manuscript. Plant Pathology New Series No. 0363, CRIS project 0678, Washington State University, Pullman, WA.

\section{LITERATURE CITED}

1. Agresti, A. 1984. Analysis of Ordinal Categorical Data. John Wiley \& Sons, New York.

2. Andrivon, D. 1994. Dynamics of the survival and infectivity to potato tubers of sporangia of Phytophthora infestans in three different soils. Soil Biol. Biochem. 26:945-952. 
3. Andrivon, D. 1994. Fate of Phytophthora infestans in a suppressive soil in relation to pH. Soil Biol. Biochem. 26:953-956.

4. Andrivon, D. 1995. Inhibition by aluminum of mycelial growth and of sporangial production and germination in Phytophthora infestans. Eur. J. Plant Pathol. 101:527-533.

5. Ann, P. J. 1994. Survey of soils suppressive to three species of Phytophthora in Taiwan. Soil Biol. Biochem. 26:1239-1248.

6. Bell, A. A., and Wheeler, M. H. 1986. Biosynthesis and functions of fungal melanins. Annu. Rev. Phytopathol. 24:411-451.

7. Blackwell, E. M., and Waterhouse, G. M. 1930. Spores and spore germination in the genus Phytophthora. Trans. Br. Mycol. Soc. 15:294-310.

8. Boguslavskaya, N. V., and Filippov, A. V. 1977. Survival rates of Phytophthora infestans (Mont) D. By. in different soils. Mikol. Fitopatol. 11:239-241.

9. Calkins, J. 1982. A method for the estimation of the penetration of biologically injurious solar ultraviolet radiation into natural waters. Pages 247-261 in: The Role of Solar Ultraviolet Radiation in Marine Ecosystems. J. Calkins, ed. Plenum Press, New York.

10. Crosier, W. 1933. Culture of Phytophthora infestans. Phytopathology 23:713-720.

11. Crosier, W. 1934. Studies in the biology of Phytophthora infestans. (Mont.) de Bary. Pages 1-40 in: Memoir 155. Cornell Univ. Agric. Exp. Stn., Ithaca, NY.

12. De Weille, G. A. 1964. Forecasting crop infection by the potato blight fungus. K. Ned. Meteorol. Inst. Meded. Verh. 82:1-144.

13. Diffey, B. L. 1991. Solar ultraviolet radiation effects on biological systems. Phys. Med. Biol. 36:299-328.

14. Dulbecco, R. 1955. Photoreactivation. Pages 455-486 in: Radiation Biology Vol. 2. Ultraviolet and Related Radiations. A. F. Hollaender, F. Daniels, J. R. Loofbourow, A. W. Pollister, and L. J. Stadler, eds. McGraw-Hill, New York.

15. Glendinning, D., MacDonald, J. A., and Grainger, J. 1963. Factors affecting the germination of sporangia in Phytophthora infestans. Trans. Br. Mycol. Soc. 46:595-603.

16. Goldstrohm, D. D., and Lilly, V. G. 1965. The effect of light on the survival of pigmented and nonpigmented cells of Dacryopinax spathularia. Mycologia 57:612-623.

17. Goodwin, S. B., Smart, C. D., Sandrock, R. W., Deahl, K. L., Punja, Z. K., and Fry, W. E. 1998. Genetic change within populations of Phytophthora infestans in the United States and Canada 1994 to 1996: Role of migration and recombination. Phytopathology 88:939-949.

18. Hill, A. E., Grayson, D. E., and Deacon, J. W. 1998. Suppressed germination and early death of Phytophthora infestans sporangia caused by pectin, inorganic phosphate, ion chelators and calcium-modulating treatments. Eur. J. Plant Pathol. 104:367-376.

19. Johnson, D. A., Alldredge, J. R., Hamm, P. B., and Frazier, B. E. 2003. Aerial photography used for spatial pattern analysis of late blight infection in irrigated potato circles. Phytopathology 93:805-812.

20. Johnson, D. A., Cummings, T. F., and Hamm, P. B. 2000. Cost of fungicides used to manage potato late blight in the Columbia Basin: 1996 to 1998. Plant Dis. 84:399-402.

21. Johnson, D. A., Cummings, T. F., Hamm, P. B., Rowe, R. C., Miller, J. S., Thornton, R. E., Pelter, G. Q., and Sorensen, E. J. 1997. Potato late blight in the Columbia Basin: An economic analysis of the 1995 epidemic. Plant Dis. 81:103-106.

22. Johnson, D. A., Martin, M., and Cummings, T. F. 2003. Effect of chemical defoliation, irrigation water, and distance from the pivot on late blight tuber rot in center-pivot irrigated potatoes in the Columbia Basin. Plant Dis. 87:977-982.
23. Jones, L. R., Giddings, N. J., and Lutman, B. F. 1912. Investigations of the potato fungus Phytophthora infestans. Pages 9-94 in: Vermont Agric. Exp. Stn. Bull. No. 168. Burlington Free Press Printing Co., Vermont.

24. King, J. E., Colhoun, J., and Butler, R. D. 1968. Changes in the ultrastructure of sporangia of Phytophthora infestans associated with indirect germination and ageing. Trans. Br. Mycol. Soc. 51:269-281.

25. Kostrowicka, M. 1959. Interaction between Phytophthora infestans and Rhizoctonia solani. Proc. 9th Int. Bot. Congr. 2:201.

26. Lacey, J. 1965. The infectivity of soils containing Phytophthora infestans. Ann. Appl. Biol. 56:363-380.

27. Larance, R. S., and Martin, W. J. 1954. Comparison of isolates of Phytophthora infestans at different temperatures. Phytopathology 44:495.

28. Martin, W. J. 1949. Strains of Phytophthora infestans capable of surviving high temperature. (Abstr.) Phytopathology 39:14.

29. McAlpine, D. 1910. Some points of practical importance in connection with the life-history stages of Phytophthora infestans (Mont.) de Bary. Ann. Mycol. 8:156-166.

30. McKee, R. K. 1964. Effect of ultraviolet irradiation on Phytophthora zoospores. Annu. Rep. John Innes Inst. 55:46-50.

31. McKee, R. K. 1965. Effects of ultraviolet radiation on zoospores of Phytophthora infestans. (Abstr.) Eur. Potato J. 8:180-181.

32. McKee, R. K. 1969. Effects of ultraviolet irradiation on zoospores of Phytophthora infestans. Trans. Br. Mycol. Soc. 52:281-291.

33. Miller, J. S., Hamm, P. B., and Johnson, D. A. 1997. Characterization of the Phytophthora infestans population in the Columbia Basin of Oregon and Washington from 1992 to 1995. Phytopathology 87:656-660.

34. Mizubuti, E. S. G., Aylor, D. E., and Fry, W. E. 2000. Survival of Phytophthora infestans sporangia exposed to solar radiation. Phytopathology 90:78-84.

35. Mizubuti, E. S. G., and Fry, W. E. 1998. Temperature effects on developmental stages of isolates from three clonal lineages of Phytophthora infestans. Phytopathology 88:837-843.

36. Murphy, P. A. 1922. The bionomics of the conidia of Phytophthora infestans. Sci. Proc. R. Dublin Soc. 16:442-466.

37. Rosenbaum, J. 1917. Studies of the genus Phytophthora. J. Agric. Res. $8: 233-276$

38. Rotem, J., and Aust, H. J. 1991. The effect of ultraviolet and solar radiation and temperature on survival of fungal propagules. J. Phytopathol. 133:76-84

39. Rotem, J., Wooding, B., and Aylor, D. E. 1985. The role of solar radiation, especially ultraviolet, in the mortality of fungal spores. Phytopathology 75:510-514

40. Salisbury, F. B., and Ross, C. W. 1992. Plant Physiology. 4th ed. Wadsworth Publishing Company, Belmont, CA.

41. Sato, N. 1994. Effect of water temperature on direct germination of the sporangia of Phytophthora infestans. Ann. Phytopathol. Soc. Jpn. 60:162-166.

42. Shaner, G., and Finney, R. E. 1977. The effect of nitrogen fertilization on the expression of slow mildewing resistance in knox wheat. Phytopathology 67:1051-1056

43. Sunseri, M. A., Johnson, D. A., and Dasgupta, N. 2002. Survival of detached sporangia of Phytophthora infestans exposed to ambient, relatively dry atmospheric conditions. Am. J. Potato Res. 79:443-450.

44. Vishtynetskaya, T. A., D’yakov, Y. T., and Zav'yalova, L. A. 1973. Effect of UV radiation on Phytophthora infestans (Mont.) de Bary. Sov. Genet. 9:36-42.

45. Warren, R. C., and Colhoun, J. 1975. Viability of sporangia of Phytophthora infestans in relation to drying. Trans. Br. Mycol. Soc. 64:73-78.

46. Zan, K. 1962. Activity of Phytophthora infestans in soil in relation to tuber infection. Trans. Br. Mycol. Soc. 45:205-221. 